\title{
Estigma relacionado ao HIV entre jovens em transição para a clínica de adultos num hospital público no Rio de Janeiro, Brasil
}

\author{
HIV-related stigma among young people living with HIV \\ transitioning to an adult clinic in a public hospital in Rio de Janeiro, \\ Brazil
}

Maria Letícia Santos Cruz (https://orcid.org/0000-0002-1559-7562) ${ }^{1}$

Mariana de Queiroz Rocha Darmont (https://orcid.org/0000-0003-3949-6886) ${ }^{1}$

Simone Souza Monteiro (https://orcid.org/0000-0003-2009-1790) ${ }^{2}$
${ }^{1}$ Hospital Federal dos Servidores do Estado. R. Sacadura Cabral 178, Saúde. 20221-903 Rio de Janeiro RJ Brasil. mleticia@diphse.com.br ${ }^{2}$ Instituto Oswaldo Cruz, Fundação Oswaldo Cruz. Rio de Janeiro RJ Brasil.

\begin{abstract}
This study analyzes how experiences of HIV-related stigma are expressed among $H I V$-positive young people transitioning to an adult clinic, the health service, the family, the affective-sexual interactions, and their relationship with inequalities and social hierarchies. This research included 31 young people (median age 21) transitioning to an adult clinic (G1) and 12 young people (median age 30) who had already made this transition (G2), both monitored at a health service in Rio de Janeiro. Seventy percent of the 43 young people were women and $65 \%$ were infected by mother-to-child transmission. Young people answered questionnaires and participated in focus groups on AIDS stigma and transition to adulthood. Most reported discrimination associated with HIV stigma in daily life and health care. G1 young people showed more significant concern about the consequences of HIV disclosure and difficulties with treatment. The G2 accounts suggest that establishing marital relationships, including HIV-negative partners and children, linked to treatment access allowed resignifying the fear of stigmatization. The findings aim to guide the training and action of professionals involved in the prevention and care of young people living with HIV.
\end{abstract}

Key words Stigma, AIDS, Young People Living with HIV, Transition to Adult Care
Resumo Neste estudo investigamos como vivências de estigma do HIV se expressam entre jovens soropositivos, em transição para a clínica de adultos, no serviço de saúde, na família e nas interações afetivos-sexuais e sua relação com as desigualdades e hierarquias sociais. O estudo envolveu 31 jovens (idade mediana 21) em transição para a clínica de adultos (G1) e 12 jovens (idade mediana 30) que já fizeram essa transição (G2), ambos atendidos num serviço de saúde do Rio de Janeiro. Dentre os 43 jovens, $70 \%$ eram mulheres e 65\% foi infectado por transmissão vertical. Os jovens responderam a questionários e participaram de grupos focais sobre estigma da aids e passagem para a vida adulta. A maioria relatou situações de discriminação associadas ao estigma do HIV na vida cotidiana e no cuidado em saúde. Os jovens do G1 revelaram maior preocupação com as consequências da revelação do HIV e dificuldades com o tratamento. Os relatos do G2 sugerem que a constituição de relações conjugais, incluindo parceiro/a e filhos soronegativos e o acesso ao tratamento, possibilitaram resignificar o receio da estigmatização. Os achados visam orientar a formação e ação de profissionais envolvidos na prevenção e cuidado de jovens vivendo com HIV. Palavras-chave Estigma, Aids, Jovens vivendo com HIV, Transição para clínica de adultos 


\section{Introdução}

Uma das importantes conquistas no enfrentamento da epidemia de aids refere-se aos avanços na terapia antirretroviral (TARV) e seu impacto no aumento da sobrevida e melhora da qualidade de vida das pessoas vivendo com HIV (PVHIV), incluindo crianças e jovens. Desse modo, as equipes envolvidas nos cuidados às crianças vivendo com HIV assistiram ao surgimento de uma população de jovens que necessitam de continuidade dos cuidados pediátricos. Em diferentes partes do mundo, profissionais de saúde, gestores e pesquisadores têm desenvolvido discussões sobre as necessidades específicas dessa população emergente $^{1-3}$. Como resultado, os serviços de saúde foram adaptados para abordar aspectos como: revelação do diagnóstico desde a infância; abertura e flexibilidade de horários para facilitar as consultas; trabalho multidisciplinar para responder às diferentes demandas; aconselhamento sobre adesão e atividades em grupo, com o objetivo de criar um ambiente de apoio onde os jovens possam desenvolver suas capacidades para lidar com as dificuldades da vida com HIV e outras questões relacionadas à adolescência.

A implementação de políticas e diretrizes para prevenção e cuidado ao jovem vivendo com HIV (JVHIV) varia em diferentes partes do mundo, em função das especificidades dos contextos locais. Apesar disso, muitos desses jovens estão chegando à idade adulta com a doença avançada e extensa resistência aos antirretrovirais, sendo que uma parcela significativa chega a abandonar o tratamento ${ }^{4-6}$. Esses aspectos precisam ser considerados no planejamento da transição dos JVHIV para a clínica de adultos, onde deverão continuar seu tratamento.

No Brasil não há uma norma rígida, em termos de idade cronológica, para que a transição para a clínica de adultos ocorra. Em geral, a equipe avalia cada jovem considerando aspectos relacionados à compreensão do diagnóstico, capacidade para discutir questões de saúde, autonomia e organização frente às demandas de seu tratamento e da vida adulta ${ }^{7}$. Prevalece a perspectiva de que a transição para a clínica de adultos é um processo que deve levar em conta aspectos subjetivos, sociais e as histórias de vida.

Nesse sentido, é preocupante constatar que, não raramente, os jovens apresentam resistências quando informados sobre a necessidade de serem acompanhados em outra clínica. As reações negativas frente ao processo de transição são expressas pela ameaça de abandono do tratamen- to e pela recusa em comparecer às consultas no ambulatório de adultos. Tais situações têm sido observadas durante as práticas de cuidado em um serviço de doenças infecciosas de um hospital público no Rio de Janeiro, onde duas autoras (MLSC e MD) atuam como profissionais da área médica e de psicologia. Convém destacar que, em geral, o processo de transição para clínica de adultos em vários centros de referência, dentro e fora do Brasil, ocorre ao longo de seis a doze meses, com consultas ambulatoriais intercaladas nos setores de jovens e de adultos. As equipes responsáveis pelos dois setores costumam interagir ao longo da transição, buscando facilitar o processo. Mas, estudos têm apontado que alguns fatores são desfavoráveis à transição, como: a dificuldade de adesão ao tratamento, o estigma do HIV, a baixa autoestima, a falta de autonomia, o abuso de substâncias e problemas de saúde mental ${ }^{7-11}$.

Frente às implicações do estigma da aids para a qualidade de vida das pessoas com HIV, o presente trabalho objetiva investigar como vivências de estigma do HIV se expressam entre jovens soropositivos, em transição para a clínica de adultos, no contexto dos serviços de saúde, das relações familiares e das interações afetivos-sexuais e sua relação com as desigualdades e hierarquias sociais. O estudo envolveu jovens vivendo com (JVHIV) em transição para clínica de adultos e jovens que já haviam feito essa transição, ambos atendidos em um hospital público do Rio de Janeiro. Os resultados do estudo visam obter subsídios para os profissionais envolvidos nas ações de prevenção e cuidado dessa população. Tal recorte se justifica tendo em vista que o estigma relacionado ao HIV é uma barreira importante ao desenvolvimento do enfrentamento adaptativo e do apoio social, incluindo a transição para clínica de adultos, pois aumenta o risco de problemas de saúde mental, reduz a autoeficácia e amplia as preocupações com a revelação do status de HIV $^{12,13}$.

A reflexão sobre as implicações do estigma relacionado ao HIV, parte do estudo pioneiro de Goffman $^{14}$, que define o estigma como um atributo desqualificante. Segundo o autor, nas interações sociais, o indivíduo com estigma tende a ser segregado das chamadas pessoas "normais", dificultando a valorização de suas outras características ${ }^{14}$. A pessoa estigmatizada pode desenvolver comportamentos inibitórios ou incorporar uma autoimagem negativa, contribuindo para o seu isolamento e reforço do estigma.

Demais autores reconhecem a relevância da conceituação sobre estigma, mas, procuram 
destacar sua função social, argumentando que o estigma desempenha um papel fundamental na produção das relações de poder e controle. $\mathrm{Ou}$ seja, a definição de um atributo como negativo, embora aparentemente arbitrária, em geral, está relacionada a padrões estéticos, sociais e culturais hegemônicos ${ }^{15,16}$. Segundo essa perspectiva, os processos de estigmatização criam barreiras que comprometem o acesso dos indivíduos ou grupos sociais estigmatizados aos bens materiais e simbólicos e contribui para manter as hierarquias e desigualdades sociais. Desse modo, a compreensão do estigma vinculado a um problema de saúde necessita levar em conta como as particularidades desse agravo se articulam com marcadores sociais da diferença como classe social, gênero, cor/raça/etnia, diversidade sexual, entre outros.

O caso do estigma relacionado à aids é exemplar. Sua origem está vinculada à associação entre a infecção pelo HIV e práticas sexuais consideradas moralmente desviantes, ao desconhecimento da comunidade cientifica frente ao novo agravo e à fatalidade da infecção no início da epidemia. Esses fatores desencadearam pânico moral e alimentaram a discriminação e a exclusão social da PVHA, dificultando o seu acesso ao cuidado continuado. Passados 40 anos, marcados por avanços biomédicos, políticos e dos direitos das PVHA, o estigma da aids ainda persiste e compromete as conquistas na área da prevenção e do cuidado. $\mathrm{O}$ que nos remete para a complexidade do fenômeno e sua vinculação com outros processos discriminatórios como homofobia, sexismo, desigualdades sociais e violência estrutural ${ }^{17}$.

Tendo em mente que o enfrentamento do estigma associado à aids deve envolver ações no âmbito micro e macro estrutural, interessa aqui destacar de que modo ele impacta na vida de PVHA. Por meio do depoimento de JVHIV, em transição ou já transferidos para clínica de adultos, tem-se o propósito de compreender como as vivências do estigma relacionado ao HIV se expressam na vida cotidiana e nos cuidados de saúde desse grupo. Os achados visam orientar a atuação dos profissionais envolvidos no processo de transição de JVHIV para clínica de adultos.

\section{Métodos}

Trata-se de um estudo transversal com dados quantitativos e qualitativos sobre jovens vivendo com HIV, acompanhados em um ambulatório de um hospital federal, em transição para a clínica de adultos ou que fizeram essa transição nos últimos anos. O hospital está localizado no Rio de Janeiro e abriga uma clínica para JVHIV desde 2000, onde os pacientes recebem atendimento interdisciplinar e participam de atividades terapêuticas em grupo. Desde 2005, o serviço também acompanha crianças vivendo com HIV.

O ambulatório do serviço de doenças infecciosas (DIP) do hospital recebe pacientes com idade mínima de 11 anos, encaminhados a partir do acompanhamento pediátrico, onde a grande maioria teve transmissão do HIV no período perinatal (transmissão vertical ou TV). O ambulório tambem recebe JVHIV encaminhados de clínicas de infecções sexualmente transmissíveis e pré-natal que tenham adquirido o HIV por via sexual (TS). Em alguns casos não é possível identificar claramente a forma de aquisição do HIV e os jovens são considerados com transmissão indeterminada (TI).

Os participantes deste estudo são JVHIV acompanhados no DIP do Hospital e com idade mínima de 18 anos. Com o propósito de compreender as experiencias de discriminação associadas ao estigma do HIV antes e após a transição para clínica de adultos, o estudo envolveu dois grupos de JVHV. O primeiro foi constituído por 31 jovens que estavam no momento de transição para a clínica de adultos, doravante denominado (G1), com idade mediana de 21 anos. O segundo grupo contou com 12 jovens, acompanhados no ambulatório, que foram transferidos o para o ambulatório de adultos nos últimos anos, doravante chamado de (G2), com idade mediana de 30 anos. $\mathrm{O}$ convite para participar na pesquisa ocorreu em ambos os grupos à medida que os jovens vinham ao serviço para suas consultas regulares.

O estudo foi aprovado pelo Comitê de Ética e Pesquisa em Seres Humanos da instituição e seguiu as diretrizes da Resolução 196/1996, do Conselho Nacional de Saúde, como a aplicação do Termo de Consentimento Livre e Esclarecido entre os participantes.

Os jovens recrutados foram convidados a participar do componente qualitativo do estudo, constituído por dois grupo focais $(\mathrm{GF})^{18,19}$, um com o G1 e outro com G2. O roteiro dos GF buscou provocar discussões sobre como eles lidam com as mudanças relacionadas à idade adulta, como expressam o que identificam como ganhos e perdas dessa fase emergente e se sentem ou percebem alguma diferença de outras pessoas devido ao fato de viverem com o HIV. Cada grupo focal foi liderado por pesquisadores (psicóloga e 
médica) e ocorreu no serviço, em área destinada às atividades em grupo. A análise temática do conteúdo dos GF foi realizada, buscando os núcleos de sentido dos temas abordados, como as mudanças decorrentes da entrada na vida adulta e as experiências de discriminação associadas ao estigma do HIV no âmbito do cuidado e das relações sociais, familiares e das interações afetivosexuais ${ }^{19}$.

Além dos grupos focais, os 46 jovens do estudo responderam aos seguintes instrumentos validados: questionário sociodemográfico, escala de estigma do HIV ${ }^{20}$ e a Escala Hospitalar de Ansiedade e Depressão ${ }^{21}$. Tais instrumentos foram aplicados por dois membros da equipe multidisciplinar (enfermeira e psicóloga). Para cada subescala da escala de estigma do HIV de Berger, foi calculado um índice, dividindo a pontuação real pela pontuação total possível para a respectiva subescala, como publicado por outros autores ${ }^{22}$. Os dados foram armazenados e analisados no SPSS versão 18.0; as frequências, médias e valores medianos foram calculados para fins descritivos. Foram também consultados os prontuários médicos desses jovens para obter resultados de carga viral e CD4. Os dados decorrentes dos instrumentos quantitativos e do prontuário tiveram o propósito de complementar, de forma pontual, as informações colhidas durante os grupos focais.

\section{Resultados e discussão}

O estudo ocorreu entre abril de 2017 e fevereiro de 2019. Durante este período, 90 jovens, com idade entre 11 e 26 anos recebiam cuidados no ambulatório para JVHIV do hospital referido na metodologia. Dos 43 jovens participantes ( 31 do G1 e 12 do G2), todos pertenciam a estratos socioeconômicos baixos, com renda média familiar de cerca de 1,7 salários mínimos brasileiros e, apesar de terem estudado em média por 14 anos, nenhum tinha ensino superior.

$\mathrm{O}$ pequeno tamanho da amostra não permite comparações estatísticas. A diferença da idade mediana entre G1 e G2, 21 e 30 anos respectivamente, por sua vez, introduz variações associadas ao momento da trajetória de vida. De qualquer modo, com base nos resultados dos instrumentos quantitativos e dos grupos focais foi possível identificar aspectos relativas à convivencia com HIV e ao tratamento dos jovens pertencentes ao G1 e ao G2, bem com sobre suas experiencias associadas ao estigma da aids.

\section{Convivendo com o HIV}

De acordo com os dados dos prontuários, a descoberta da infecção do HIV entre os JVHIV do G1 e G2 foi variada, alguns ocorreram na infância e outros na adolescência. Como argumentam Cruz et al. ${ }^{11}$ o momento da revelação do diagnóstico HIV e o contexto social e familiar influenciam o processo de socialização primária de crianças e adolescentes infectados e, consequentemente, as suas experiencias sobre a condição de ser portador do HIV. Segundo os autores, adolescentes assintomáticas, submetidas ao teste de HIV em função do diagnóstico de soropositividade da mãe ou do pai, tem reações diversas; alguns aderem ao tratamento, enquanto outros tem dificuldade em aceitar essa nova condição.

Os dados colhidos no presente estudo não contemplam um maior detalhamento sobre a trajetória de vida dos $46 \mathrm{JVHA}$ que integram o estudo, mas possibilitam identificar vivências relacionadas ao estigma do HIV ao longo da vida. Como indicam os dados percentuais da Tabela 1, os jovens do G1 e G2 apresentam semelhanças em relação ao nivel de ansiedade e depressão, bem como aos escores da escala Berger para estigma relacionado ao HIV. Tal escala é composta por 40 perguntas relativas às experiências de rejeição, à preocupação com a revelação, à autoimagem negativa e à percepção de rejeição social associada ao HIV, que tem como opção de resposta 4 opções: discordo totalmente, discordo, concordo e concordo totalmente.

A análise dos depoimentos durante os dois grupos focais com jovens do G1 e do G2 igualmente indicaram situações de discriminação no contexto do cuidado em saúde em anos recentes. Os participantes de ambos os grupos relataram atitudes hostis por parte de profissionais de saúde seja no período de internação ou na experiência de atendimento médico. Os relatos a seguir são ilustrativos:

...o que eu passei foi muito preconceito na maternidade que meu filho nasceu, era muito preconceito, era coisa de enfermeira chegar para mim e falar assim: "Ó, quantos anos você tem?", eu falava assim, "ah, dezesseis", "você acabou com a sua vida tá, nunca mais faz nada sem camisinha". Era isso, é assim, toda hora vinha e tacava pedra de gelo no meu peito e eu estava num quarto onde não tinha outras pessoas com HIV, eu era a única, todo mundo amamentando que era uma coisa que ainda mexe comigo que eu quero amamentar... Porque a mulher que é grávida e tá com HIV é um pouco diferente da normal. (M. 21 anos, fem, TS, G1). 
Tabela 1. Descrição das características dos jovens incluídos no estudo: G1 (em transição para a clínica de adultos) e G2 (haviam feito a transição nos últimos anos).

\begin{tabular}{|c|c|c|}
\hline Característica & G1 & G2 \\
\hline Mediana idade & $21[\mathrm{IQR}=19-22]$ & $30[\mathrm{IQR}=25-31]$ \\
\hline Sexo feminino & $68 \%$ & $83 \%$ \\
\hline Não brancos & $77 \%$ & $100 \%$ \\
\hline $\begin{array}{l}\text { Adquiriram } \\
\text { HIV por TV* }\end{array}$ & $71 \%$ & $50 \%$ \\
\hline $\begin{array}{l}\text { Não está } \\
\text { trabalhando }\end{array}$ & $74 \%$ & $59 \%$ \\
\hline $\begin{array}{l}\text { Carga viral } \\
\text { indetectável no } \\
\text { último exame }\end{array}$ & $48 \%$ & $50 \%$ \\
\hline Ansiedade & $57 \%$ & $54 \%$ \\
\hline Depressão & $13 \%$ & $15 \%$ \\
\hline $\begin{array}{l}\text { Escala de Berger } \\
\text { para estigma } \\
\text { relacionado ao } \\
\text { HIV }\end{array}$ & & \\
\hline $\begin{array}{l}\text { Experiências de } \\
\text { rejeiçãõ }\end{array}$ & 0,56 & 0,6 \\
\hline $\begin{array}{l}\text { Preocupação cl } \\
\text { revelação }\end{array}$ & 0,66 & 0,7 \\
\hline $\begin{array}{l}\text { Autoimagem } \\
\text { negativa }^{* *}\end{array}$ & 0,7 & 0,67 \\
\hline $\begin{array}{l}\text { Percepção } \\
\text { rejeição social** }\end{array}$ & 0,67 & 0,65 \\
\hline
\end{tabular}

${ }^{\star}$ TV: Transmissão vertical. ${ }^{\star *}$ Os escores foram calculados dividindo a pontuação real pela pontuação total possível para a respectiva subescala.

Fonte: Elaborado pelas autoras.

$E$ E, me botaram numa sala separada por causa que eu tenho isso [HIV] e eles falaram que lá tem gente com isso e as pessoas têm que ficar na sala separada", e fora que a mulher não queria fazer o curativo. (A.22 anos,TV, fem, G1).

(...) aí o médico falou que, ah, "porque ela é soro positivo, porque esse povo assim tinha que morrer, que isso, que aquilo"... (S. 30 anos, fem, TV, G2).

Embora tais situações não possam ser generalizadas, chama a atenção a recorrência desses depoimentos entre os JVHIV do G1 e G2 e seus efeitos na atualização das experiências de discriminação das PVHA. De acordo com duas autoras do presente estudo (MLSC e MD), que atuam no atendimento de JVHIV, como já referido, é comum que jovens com diagnóstico recente ou que não apresentam boa adesão ao tratamento faltem às consultas. Na visão das mesmas, a não frequência ao serviço pode estar relacionada ao receio deles serem julgados pelos profissionais de saúde.

Demais pesquisas têm registrado práticas discriminatórias de profissionais de saúde com as PVHIV ${ }^{23-26}$. Um dos trabalhos ${ }^{23}$, realizado nos EUA, destaca que as práticas estigmatizantes dos profissionais podem ser desencadeadas pelo medo, falta de treinamento e educação específica sobre o HIV e contato limitado com PVHA. Os estudos e achados descritos apontam para a necessidade e importância de investimentos na formação profissional, aliada a intervenções culturais voltadas para visibilidade do estigma da aids, que têm sido escassas em anos recentes.

Ainda com relação ao impacto da estigmatização para as pessoas portadoras de marcas indesejáveis, estudos assinalam que tais situações fomentam avaliações negativas sobre si e auto rejeição; além de poderem ameaçar a identidade social do sujeito ou grupo social estigmati$\mathrm{zado}^{27,28}$. No caso do estigma do HIV, pesquisas atestam reações de culpa, vergonha, medo, raiva e recusa em aceitar o diagnóstico, capazes de causar depressão e exclusão social ${ }^{29}$ e comprometer a adesão ao tratamento.

Nesse sentido, cabe ressaltar que foi observado que os participantes do G1 indicaram maior receio em relação às consequências da revelação do seu status de HIV, quando comparado aos integrantes do G2. As falas a seguir exemplificam experiências e visões acerca do temor da revelação do diagnóstico:

Tipo, igual eu, eu tinha uma melhor amiga, eu acho que ela era minha melhor amiga aí no final ela me ferrou, entendeu? Ela meio que contou para rua toda o que eu tenho, para ter uma amizade assim eu prefiro ter inimigo. (A. 22 anos, fem, TV, $\mathrm{G} 1)$.

Eu não falo nada. Acho que hoje eu estou pronta já para abrir a boca e falar, se alguém perguntar, se alguém descobrir. Às vezes eu tenho até vontade de botar lá no facebook (...) na verdade se eu falar vai ser um choque né "como assim?" (...). Dá vontade mais de falar quando eu estou bêbada, pô, vontade de pegar o microfone "alô, alô..." (...), quase sai, mas nunca sai, mas no dia que eu contar todo mundo vai achar que eu estava bêbada falando besteira porque eu falo besteira mesmo. (T. 25 anos, fem, TV, G1).

Estudo prévio com crianças e adolescentes vivendo com HIV, em diferentes regiões do Brasil ${ }^{30}$, confirma demais dados da literatura que indicam que a dificuldade da revelação tende a comprometer a adesão ao tratamento. Assim, é impor- 
tante considerar que os jovens do G1 relataram maior desconforto com o uso continuado da medicação. Uma participante do G1, de 20 anos, teve um diagnóstico tardio de transmissão vertical aos 12 anos, descoberto por ocasião de uma nova gravidez da mãe que resultou na testagem dos demais familiares. Ela relata que o uso da medicação provoca nela uma aparência de pessoa anêmica por deixar seu "olho amarelo". Como reação, oculta a infecção do HIV, preferindo dizer que passa por dificuldade econômica: "lá em casa não tem comida não, tá fogo, o desemprego está aí né?”.

Uma outra participante do G1 de 25 anos, teve seu diagnóstico e sua adoção revelados em plena adolescência, aos 15 anos. Desde então, afirma que é diferente das demais pessoas, por ter que frequentar consultas médicas e tomar medicação para garantir a sua sobrevivência. $\mathrm{Na}$ sua fala: "eu tenho que ir no médico, eu tomo remédio, se eu não tomo remédio eu morro, eu dependo de remédio e de dois".

Depreende-se que o uso continuado de um remédio ao longo da vida, em geral, pode promover desconfortos decorrentes de efeitos colaterais e da frequência do acompanhamento médico. Todavia, em função do estigma da aids, as pessoas com HIV em tratamento convivem com o receio de serem discriminadas se revelarem sobre a infecção. Isto significa dizer que mesmo quando há o reconhecimento dos benefícios do uso continuado da medicação para manutenção das condições de vida, tal processo pode ser interrompido pelo medo da descoberta da soropositividade.

Como já descrito por Goffman ${ }^{14}$, as reações ao processo de estigmatização podem ser o isolamento social e a autodepreciação, bem como o gerenciamento da marca indesejável, pelo seu ocultamento ou correção, na busca por aceitação social e redução das tensões nas interações com os ditos "normais". A não revelação do diagnóstico do HIV ilustra essa tentativa de apagamento da marca estigmatizante. Todavia, há outras formas de reação dos estigmatizados, como a formação de redes de ajuda e apoio mútuo e a ação política por meio da luta por direitos das pessoas portadoras do estigma. O histórico das respostas do movimento social das PVHA é ilustrativo desses fenômenos ${ }^{31}$. A fragilização atual do movimento social de aids no contexto nacional, em parte pela redução de recursos, tem comprometido as ações de controle social e formulação de discursos e práticas de prevenção e cuidado, incluindo o enfrentamento do estigma da aids.

\section{Resignificação do estigma da aids após a transição para clinica de adultos}

A despeito das semelhanças assinaladas entre os membros do G1 e do G2, foram identificadas diferenças. Uma delas refere-se ao item 'não estar trabalhando' da Tabela 1, cujo percentual do G1 (74\%) é maior que o G2 (59\%). O fato da idade mediana dos jovens do G2 ser superior ao G1, 21 e 30 anos respectivamente, sugere que há maior possibilidade dos membros do G2 estarem exercendo uma atividade laboral.

Uma outra diferença entre os dois grupos diz respeito ao fato dos depoimentos dos jovens do G2 não referirem problemas associados ao uso continuado do tratamento, como relatado pelo G1 no item acima. Ademais, os relatos dos JVHIV do G2 sugerem que a constituição de relações conjugais, incluindo parceiro/a e filhos soronegativos, vinculada ao acesso ao tratamento, possibilita resignificar o receio da estigmatização do HIV e, de algum modo, superar o histórico de adoecimento, decorrentes da infecção e o medo da transmissão. Os relatos abaixo são ilustrativos:

Mas não tenho que reclamar não, não tive pai, mãe desde criança, fui criada no abrigo, depois o juizado de menores mandou eu ir morar com minha tia já praticamente adolescente, fiquei um bom tempo também, o eu senti na pele o que é ficar... adoecer de uma hora para outra porque você corre atrás do remédio porque não existia remédio para você, ficar sendo jogada de um hospital para o outro, entrando em testes e mais testes e você se sentia ruim. E a minha vida adulta depois que minha filha nasceu para mim está sendo mais tranquilo na questão de remédio, eu não tenho a doença do nada, então para mim é... o marido que não é soropositivo também não tem nada, ele ajuda bastante, a gente tem a casa própria agora, tudo bonitinho nossa filha já está lendo, tá enorme e é o valor que a gente tem que dar quem ajudou a gente quando era adolescente... (S. 30 anos, fem, TV, G2).

No começo não, vamos botar nos primeiros cinco (...) às vezes eu pensava, eu ia namorar aí eu olhava assim, ai meu Deus não sei o que, vai ser diferente, tenho que usar camisinha porque se não usar, aí eu passo para o cara e o cara vai descobrir vai querer me matar que não sei o que (...) porque graças a Deus hoje em dia eu tenho minha família, tenho meu marido, meu marido não é soropositivo entendeu, todo ano ele faz o exame direitinho. Uma coisa também que me incentiva muito a tomar remédio, é me cuidar para mim não transmitir para ele, também é um incentivo e. mas hoje eu não me sinto não, diferente de ninguém não, hoje eu 
chego num lugar, onde eu estou quem souber sabe e se não souber e também não quiser saber eu pego e falo, para mim não faz diferença se souber que eu tenho e se não souber não faz diferença não. (P. 30 anos, fem, TS, G2).

...quando eu conheci minha esposa eu senti tanta confiança nela que eu acho que com dois dias de namoro eu cheguei no quarto, "cara vamos conversar", eu expliquei para ela, com o medo que eu tinha, sei lá, por parte dela de me abandonar e tal, ai simplesmente ela me abraçou, levantamos e fomos sair. Ela sempre me deu maior apoio, "pô, estamos juntos!" Hoje eu tento me cuidar, mas eu me cuido, mas às vezes é para não passar para ela né. (M. 25 anos, masc, TI, G2).

Esses depoimentos convergem com os resultados de um estudo que explorou as experiências íntimas de relacionamento de 1.334 mulheres vivendo com HIV no Canadá onde foi observado que mulheres com parceiros soronegativos tinham maiores sentimentos de normalidade e aquelas em relacionamentos felizes a longo prazo eram menos propensas a experimentar estigma ${ }^{32}$. Embora a causalidade dessas observações não possa ser determinada, para os autores os efeitos da relação amorosa e da intimidade no bem-estar psicológico podem, em parte, explicar esses achados. Por outro lado, a associação entre a dificuldade de estabelecer relações afetivo-sexuais e o receio da estigmatização associada ao HIV foi evidenciada em estudos com jovens HSH em Chicago $^{22}$ e da África do Sul ${ }^{33}$. Segundo os achados, os jovens que temem a rejeição devido ao seu status de HIV têm maior probabilidade de serem socialmente isolados e não se envolverem em relações românticas.

Nesta direção, é interessante destacar que parte dos jovens que fizeram a transição estava envolvida em relacionamentos afetivos com parceiros/as soronegativos. Eles experimentaram a maternidade/paternidade com perspectiva de não transmissão do HIV para os seus filhos, tendo em vista o acesso aos medicamentos capazes de evitar a transmissão vertical. Isto significa dizer que eles tiveram uma oportunidade de prevenção do HIV no contexto da reprodução que suas mães não tiveram.

Pode-se supor que o estabelecimento de relações conjugais, a geração de filhos soronegativos (em função da prevenção da transmissão vertical) e a ausência de sinais da infecção do HIV (decorrentes do tratamento), aproximam a PVHIV de um padrão definido como "normal". Essas situações colaboram para apagar a "marca" estigmatizante da aids que, ao longo da vida, ge- raram situações de discriminação. Considerando que diversos estudos atestam que as expêriencias de estigmatização associadas ao HIV são comuns e geram sofrimento, é compreensível que o apagamento de marcas estigmatizantes reduza as situações de discriminação e sejam almejadas pelas PVHIV.

Todavia, como argumenta Monteiro et al. ${ }^{34}$, é preciso salientar que a falta de visibilidade dos fatores que deram origem e fomentam o estigma da aids, assinalados na introdução, contribuem para a sua persistência. Ou seja, o enfrentamento da estigmatização pelo ocultamento ou apagamento da marca pode reduzir o sofrimento das pessoas estigmatizadas; todavia, não favorece que se questione o que torna essa marca algo excepcional para ser escondido. Desse modo, é importante reconhecer que a desconstrução do estigma da aids não resultará de ações individuais isoladas das PVHIV e sim de um esforço coletivo, por meio de políticas e intervenções culturais e estruturais ${ }^{17}$. Nesse sentido, é preocupante a ausência de investimentos contínuos no enfrentamento do estigma e das condições de vulnerabilidade ao HIV das atuais diretrizes, nacional e internacional, de resposta à epidemia de aids. Tal reconhecimento tem motivado propostas de ações nessa direção ${ }^{35}$.

\section{Considerações finais}

Os resultados do estudo com jovens soropositivos, em transição ou já transferidos para clínica de adultos, possibilitam uma melhor compreensão dos desafios da vida com HIV entre jovens e seus efeitos em diferentes estágios da progressão para a idade adulta. E, desse modo, pode orientar a formação e ação de profissionais envolvidos na prevenção e cuidado de JVHIV.

O fato dos JVHIV em transição para a clínica de adultos indicarem uma maior preocupação sobre a revelação do diagnóstico, capaz de afetar a adesão ao tratamento e a transição para clínica de adultos, sugere a importância dos serviços de saúde abordarem esse tema. Nessa perspectiva, propõe-se que os profissionais promovam um diálogo continuado com JVHIV acerca dos fatores envolvidos no surgimento do estigma da aids, as razões de sua persistência e as possibilidades de enfrentamento no âmbito micro e macro. Pode ser pertinente envolver nessa dinâmica os jovens que já concluíram a transição para que eles compartilhem das suas trajetórias de convívio com o HIV, incluindo a situação atual em ter- 
mos das perspectivas de conjugalidade, maternidade/paternidade, inserção laboral e dos desafios da vida adulta. Vale salientar que a ressignificação da fatalidade da aids e ampliação da perspectiva de vida das PVHA foi um dos fatores associados a maior adesão ao tratamento segundo pesquisa com crianças e adolescentes com HIV, de unidades de tratamento de aids pediátrica de cinco macrorregiões brasileiras ${ }^{30}$.

Como argumentado, o estigma da aids é um fenômeno complexo cuja persistência tem comprometido o alcance das conquistas relevantes no campo da prevenção e do cuidado. Seu enfrentamento envolve intervenções estruturais, culturais e psicossociais. Os profissionais de saúde envolvidos na prevenção e cuidado das PVHIV tem potencial para colaborar na desnaturalização desse fenômeno. Para tanto, faz-se necessário reconhecer a origem e função social do estigma da aids e investir na formação continuada capaz de abordar a dimensão histórica, cultural, socioeconômica e política da epidemia, para além da intervenção biomédica.

Certamente este é um grande desafio, haja vista que tais aspectos em geral não são contemplados nas graduações e especializações dos profissionais em saúde. Todavia, as quatro décadas da epidemia forneceram lições e aprendizados, capazes de orientar a abordagem desses temas na formação das equipes e, consequentemente, na atuação dos serviços de saúde que atuam com PVHIV.

\section{Colaboradores}

MLS Cruz propôs o trabalho, apresentou a versão inicial do projeto, coordenou os GF, trabalhou na análise dos conteúdos dos GF, e apresentou a versão inicial do manuscrito final. MQR Darmont contribuiu na redação e desenvolvimento do projeto, coordenou a coleta de dados fez a observação dos grupos focais, trabalhou na análise dos conteúdos dos GF, contribuiu na redação da versão final do manuscrito. SS Monteiro contribuiu na redação e desenvolvimento do projeto, trabalhou na análise dos conteúdos dos GF, contribuiu na redação da versão final do manuscrito. 


\section{Referências}

1. Hoffman ND, Futterman D, Myerson A. Treatment issues for HIV-positive adolescents. AIDS Clin Care 1999; 11(3):17-19.

2. Futterman D, Charbon B, Hoffman ND. HIV and AIDS in adolescents. Pediatr Clin North Am 2000; 47(1):171-188.

3. Brasil. Ministério da Saúde (MS). Secretaria de Vigilância em Saúde. Programa Nacional de DST e Aids. Manual de rotinas para assistência de adolescentes vivendo com HIV/Aids. Brasília: MS; 2006.

4. Foster C, Judd A, Tookey P, Tudor-Williams G, Dunn D, Shingadia D, Lyall H. Collaborative HIV Pediatric Study (CHIPS). Young people in the United Kingdom and Ireland with perinatally acquired HIV: The pediatric legacy for adult services. AIDS Patient Care STDS 2009; 23:159-166.

5. Agwu AL, Fairlie L. Antiretroviral treatment, management challenges, and outcomes in perinatally HIV -infected adolescents. J Int AIDS Soc 2013; 16:18579.

6. Agwu AL, Lee L, Fleishman JA, Voss C, Yehia BR, Althoff KN, Gebo KA. Aging and Loss to Follow-up Among Youth Living with Human Immunodeficiency Virus in the HIV Research Network. J Adolesc Health 2015; 56:345-351.

7. Machado DM, Succi RC, Turato ER. Transitioning adolescents living with HIV/AIDS to adult-oriented health care: an emerging challenge. J Pediatr 2010; 86:465-472.

8. Vijayan T, Benin AL, Wagner K, Romano S, Warren WA. We Never Thought This Would Happen: Transitioning Care of Adolescents with Perinatally-Acquired HIV Infection from Pediatrics to Internal Medicine. AIDS Care 2009; 21:1222-1229.

9. Cervia JS. Easing the Transition of HIV- Infected Adolescents to Adult Care. Behavioral and Psychosocial Research. Aids Patient Care STDs 2013; 27:692-696.

10. Cruz MLS, Cardoso CA, Darmont M, Souza ES, Dourado S, Fabbro M, Fonseca R, Bellido JG, Monteiro SS, Bastos FI. Viral suppression and adherence among HIV-infected children and adolescents on antiretroviral Therapy: results of a multicenter study. J Pediatr 2014; 90(6):563-572.

11. Cruz MLS, Bastos FI, Darmont M, Dickstein P, Monteiro SS. The moral career of perinatally HIV-infected children: revisiting Goffman's concept. AIDS Care 2015; 1:6-9.

12. Katz IT, Ryu AE, Onuegbu AG, Psaros C, Weiser SD, Bangsberg DR, Alexander C, Tsai AC. Impact of HIV-related stigma on treatment adherence: systematic review and meta-synthesis. J Int AIDS Soc 2013; 16(Supl. 2):18640.

13. Sweeney S, Vanable P. The association of HIV-related stigma to HIV medication adherence: a systematic review and synthesis of the literature. AIDS Behav 2016; 20:29-50.

14. Goffman E. Estigma. Notas sobre a manipulação da identidade deteriorada. Rio de Janeiro. Ed. Zahar; 1980.

15. Link B, Phelan J. Conceptualizing Stigma. Annu Rev Sociol 2001; 27:363-385.

16. Parker R, Aggleton P. HIV and AIDS-related stigma and discrimination: a conceptual framework and implications for action. Soc Sci Med 2003; 57:13-24.
17. Parker R. Stigma, prejudice and discrimination in global public health. Cad Saude Publica 2012; 28:164169.

18. Flick U. Managing Quality in Qualitative Research. London, New Delhi, Singapore: Sage Publications, Thousand Oaks; 2008.

19. Minayo MCS. O desafio do conhecimento: pesquisa qualitativa em saúde. São Paulo: Hucitec; 2010.

20. Berger BE, Ferrans CE, Lashley FR. Measuring Stigma in People With HIV: Psychometric Assessment of HIV Stigma Scale. Res Nurs Health 2001; 24:518-529.

21. Zigmond AS, Snaith RP. The hospital anxiety and depression scale. Acta Psychiat 1983; 67:361-370.

22. Dowshen N, Binns J, Garofalo R. Experiences of HIV-Related Stigma Among Young Men Who Have Sex with Men. Aida Patient Care STDs 2009; 23(5):371376.

23. Davtyan M, Olshansky EF, Brown B, Lakon C. A grounded theory study of HIV-related stigma in U.S. -based health care settings. J Assoc Nurses AIDS Care 2017; 28(6):907-922.

24. Magnus M, Herwehe J, Murtaza-Rossini M, Reine P, Cuffie D, Gruber D, Kaiser M. Linking and retaining HIV patients in care: The importance of provider attitudes and behaviors. AIDS Patient Care STDs 2013; 27(5):297-303.

25. Mill J, Harrowing J, Rae T, Richter S, Minnie K, Mbalinda S, Hepburn-Brown C. Stigma in AIDS nursing care in Sub-Saharan Africa and the Caribbean. Qual Health Res 2013; 23(8):1066-1078.

26. Hassan ZM, Wahsheh MA. Knowledge and attitudes of Jordanian nurses towards patients with HIV/AIDS: Findings from a nationwide survey. Issues Ment Health Nurs 2011; 32(12):774-784.

27. Major B, O’Brien LT. The social psychology of stigma. Annu Rev Psychol 2005; 56:393-421.

28. Dickerson SS, Gruenewald TL, Kemeny ME. When the social self is threatened: shame, physiology, and health. J Pers 2004; 72(6):1191-1216.

29. Bennett DS, Hersh J, Herres J, Foster J. HIV-Related Stigma, Shame, and Avoidant Coping: Risk Factors for Internalizing Symptoms Among Youth Living with HIV? Child Psychiatry Hum Dev 2016; 47(4):657-664.

30. Cruz ML Cardoso C, Darmont M, Dickstein P, Bastos F, Souza E, Andrade S, D'All Fabbro M, Fonseca R, Monteiro S. Children and adolescents with perinatal HIV-1 infection: factors associated with adherence to treatment in the Brazilian context. Int J Environ Res Public Health 2016; 13(6):615.

31. Ramos S. O papel das ONGs na construção de políticas de saúde: a aids, a saúde da mulher e a saúde mental. Cien Saude Colet 2010; 9(4):1067-1078.

32. Carter A, Greene S, Money D, Sanchez M, Webster K, Nicholson V, Kaida A, on behalf of the CHIWOS Research Team. Love with HIV: A Latent Class Analysis of Sexual and Intimate Relationship Experiences Among Women Living with HIV in Canada. Arch Sex Behav 2019; 48(4):1015-1040.

33. Toska E, Cluver LD, Hodes R, Kidia KK. Sex and secrecy: How HIV-status disclosure affects safe sex among HIV-positive adolescents. AIDS Care 2015; 27(Supl. 1):47-58, 
34. Monteiro S, Villela W, Soares P, Pinho A, Fraga L. Protective silence surrounding AIDS: Reasons and implications of non-disclosure among pregnant women living with HIV in Rio de Janeiro (Brazil). Glob Public Health 2018; 13(1):51-64.

35. Stangl A, Earnshaw V, Lodgie C, Brakel W, Simbayi L, Barré I, Dovidio J. The Health Stigma and Discrimination Framework: a global, crosscutting framework to inform research, intervention development, and policy on health-related stigmas. BMC Med 2019; 17(1):31.

Artigo apresentado em 28/04/2020

Aprovado em 31/03/2021

Versão final apresentada em 02/04/2021

Editores-chefes: Romeu Gomes, Antônio Augusto Moura da Silva 